\title{
A comparative study of the preventative effects exerted by two probiotics, Lactobacillus reuteri and Lactobacillus fermentum, in the trinitrobenzenesulfonic acid model of rat colitis
}

\author{
Laura Peran ${ }^{1}$, Saleta Sierra ${ }^{2}$, Mònica Comalada ${ }^{1}$, Federico Lara-Villoslada ${ }^{2}$, Elvira Bailón ${ }^{1}$, Ana Nieto ${ }^{3}$, \\ Ángel Concha ${ }^{4}$, Mónica Olivares ${ }^{2}$, Antonio Zarzuelo ${ }^{1}$, Jordi Xaus ${ }^{2}$ and Julio Gálvez ${ }^{1}$ * \\ ${ }^{1}$ Department of Pharmacology, University of Granada, Campus Universitario 'La Cartuja' s/n, 18071 Granada, Spain \\ ${ }^{2}$ Department of Immunology and Animal Sciences, Puleva Biotech SA, Granada, Spain \\ ${ }^{3}$ Andalusian Stem Cell Bank, Health and Progress Foundation, Granada, Spain \\ ${ }^{4}$ Department of Pathology, Hospital Universitario 'Virgen de las Nieves', Granada, Spain
}

(Received 18 April 2006 - Revised 23 August 2006 - Accepted 19 September 2006)

\begin{abstract}
The intestinal anti-inflammatory effects of two probiotics isolated from breast milk, Lactobacillus reuteri and L. fermentum, were evaluated and compared in the trinitrobenzenesulfonic acid (TNBS) model of rat colitis. Colitis was induced in rats by intracolonic administration of $10 \mathrm{mg}$ TNBS dissolved in $50 \%$ ethanol $(0.25 \mathrm{ml})$. Either L. reuteri or L. fermentum was daily administered orally $\left(5 \times 10^{8}\right.$ colony-forming units suspended in $0.5 \mathrm{ml}$ skimmed milk) to each group of rats $(n 10)$ for 3 weeks, starting 2 weeks before colitis induction. Colonic damage was evaluated histologically and biochemically, and the colonic luminal contents were used for bacterial studies and for SCFA production. Both probiotics showed intestinal anti-inflammatory effects in this model of experimental colitis, as evidenced histologically and by a significant reduction of colonic myeloperoxidase activity $(P<0 \cdot 05)$. L. fermentum significantly counteracted the colonic glutathione depletion induced by the inflammatory process. In addition, both probiotics lowered colonic TNF $\alpha$ levels $(P<0 \cdot 01)$ and inducible NO synthase expression when compared with non-treated rats; however, the decrease in colonic cyclo-oxygenase-2 expression was only achieved with L. fermentum administration. Finally, the two probiotics induced the growth of Lactobacilli species in comparison with control colitic rats, but the production of SCFA in colonic contents was only increased when L. fermentum was given. In conclusion, L. fermentum can exert beneficial immunomodulatory properties in inflammatory bowel disease, being more effective than L. reuteri, a probiotic with reputed efficacy in promoting beneficial effects on human health.
\end{abstract}

Probiotics: Inflammatory bowel diseases: Immunomodulation: Anti-inflammatory activity

Several studies have proposed that breast-feeding protects against many immune-mediated diseases, including those related to inflammatory bowel diseases (IBD) such as ulcerative colitis and Crohn's disease (Klement et al. 2004). These observations confirm previous studies in which breast-milk feeding limited the development of colitis in IL-10 knockout mice. This finding was explained by a change in the intestinal flora of the developing mice from pathogenic bacteria to non-adherent bacteria, promoted by milk oligosaccharides that stimulate Bifidobacterium and Lactobacillus growth (Kunz et al. 2000). In addition, the presence of lactic bacteria in breast milk could also account for its preventative effect against intestinal inflammation (Martin et al. 2003).

In fact, the administration of probiotic micro-organisms has been proposed to promote a balanced colonic microbial environment and thus probably help in both prevention and control of IBD. Previous studies have reported that the administration of a mixture of bifidobacteria and lactobacilli
(Venturi et al. 1999) or Escherichia coli Nissle 1917 (Rembacken et al. 1999) prevents the relapse of ulcerative colitis, showing the latter to have an equivalent effect to mesalazine in maintaining remission. The studies performed both in human subjects and in animal models of intestinal inflammation have provided some clues about the different mechanisms involved in the therapeutic effects exerted by probiotic micro-organisms. First, probiotics could suppress the growth or epithelial binding and invasion of enteric pathogenic bacteria, maybe due to their ability to decrease luminal $\mathrm{pH}$ via production of SCFA (Sakata et al. 2003), promote the secretion of bactericidal proteins (Boris et al. 2001; Collado et al. 2005) and/or stimulate mucin production (Mack et al. 1999). Second, probiotics have been reported to exert immunoregulatory activities, either by inducing protective cytokines, such as IL-10 and transforming growth factor- $\beta$, or by suppressing pro-inflammatory cytokines, such as TNF $\alpha$, in the intestinal mucosa (Borruel et al. 2002; Schultz et al.

\footnotetext{
Abbreviations: COX-2, cyclo-oxygenase-2; IBD, inflammatory bowel disease; iNOS, inducible NO synthase; LTB 4 , leukotriene B4; MPO, myeloperoxidase; TNBS, trinitrobenzenesulfonic acid.

*Corresponding author: Dr Julio Galvez, fax +34 958248964, email jgalvez@ugr.es
} 
2003; Pathmakanthan et al. 2004; Chen et al. 2005). And third, these micro-organisms positively affect the intestinal barrier function by decreasing mucosal permeability (Madsen et al. 2001). However, the detailed mechanisms by which these bacteria mediate their effects are not fully understood.

The aim of the present study was to compare the preventative effects of Lactobacillus fermentum CECT5716 and $L$. reuteri ATCC55730, two hetero-fermentative bacteria found in breast milk (Martin et al. 2005; BioGaia, 2006), in the trinitrobenzenesulfonic acid (TNBS) model of rat colitis. This is a well-established model of intestinal inflammation with some resemblance to human IBD (Jurjus et al. 2004). The selection of the probiotics was based on previous in vitro and in vivo studies that make them suitable candidates for the treatment of these intestinal conditions. In a previous study, we have reported that L. fermentum CECT5716 showed intestinal anti-inflammatory activity in the TNBS model of rat colitis (Peran et al. 2006). That effect was attributed, at least partially, to its ability to release glutathione and the antioxidant dipeptide $\gamma$-Glu-Cys, thus counteracting the damaging effects derived from the intestinal oxidative stress generated (Grisham et al. 1991), similarly to what occurs in human IBD (Grisham, 1994). This effect was also associated with a reduction in $\mathrm{TNF} \alpha$ production and in inducible NO synthase (iNOS) expression in the inflamed tissue (Peran et al. 2006). On the other hand, different strains of $L$. reuteri have been described to show beneficial effects in several experimental models of colitis, both in mice (IL-10 and $\mathrm{CD} 4^{+} \mathrm{T}$ cell-induced colitis in the severe combined immunodeficient mouse) (Madsen et al. 1999; Moller et al. 2005), and in rats (acetic acid- and methothrexate-induced) (Mao et al. 1996; Holma et al. 2001). In vitro studies have shown that $L$. reuteri DSM12246 is able to down regulate the stimulated production of the pro-inflammatory cytokines IL-12 and $\mathrm{TNF} \alpha$ in dendritic cells while inducing the anti-inflammatory cytokine IL-10 (Christensen et al. 2002). Similarly, another strain of $L$. reuteri inhibited mRNA up regulation, cellular accumulation and secretion of the chemokine IL- 8 induced by $\mathrm{TNF} \alpha$ in intestinal epithelial cells (Ma et al. 2004).

\section{Materials and methods}

The present study was carried out in accordance with the 'Guide for the Care and Use of Laboratory Animals' as promulgated by the National Institute of Health (Bethesda, MD, USA).

\section{Reagents}

All chemicals were obtained from Sigma Chemicals (Madrid, Spain), unless otherwise stated.

\section{Preparation and administration of the probiotics}

L. fermentum CECT5716 was provided by Puleva Biotech (Granada, Spain), L. reuteri ATCC55730 was obtained from a commercial dairy product licensed by BioGaia AB (Stockholm, Sweden). Lactobacilli strains were normally grown in De Man-Rogosa-Sharpe (MRS) media at $37^{\circ} \mathrm{C}$ in anaerobic conditions using the Anaerogen system (Oxoid Ltd,
Basingstoke, Hants, UK). For probiotic treatment, bacteria were suspended in skimmed milk $\left(10^{9}\right.$ colony-forming units/ $\mathrm{ml})$ and stored at $-80^{\circ} \mathrm{C}$ until usage.

\section{Experimental design}

Female Wistar rats (180-200g) were obtained from the Laboratory Animal Service of the University of Granada (Granada, Spain), maintained in standard conditions and fed the Panlab A04 diet (Panlab, Barcelona, Spain) ad libitum. The composition of the diet was: $17.2 \%$ protein, $2.7 \%$ fat, $59.7 \%$ carbohydrates, $3.9 \%$ fibre (mainly cellulose), $4.4 \%$ minerals and $12 \%$ humidity. The rats were randomly assigned to four groups ( $n$ 10); two of them (non-colitic and control groups) did not receive probiotic treatment and the remaining groups (treated groups) received orally each probiotic $\left(5 \times 10^{8}\right.$ colony-forming units suspended in $0.5 \mathrm{ml}$ skimmed milk) daily for 3 weeks. Both non-colitic and control groups received orally the vehicle used to administer the probiotic $(0.5 \mathrm{ml}$ daily). At 2 weeks after starting the experiment, the rats were fasted overnight and those from the control and treated groups were rendered colitic by the method originally described by Morris et al. (1989). Briefly, they were anaesthetised with halothane and given $10 \mathrm{mg}$ TNBS dissolved in $0.25 \mathrm{ml}$ ethanol $(50 \%, \mathrm{v} / \mathrm{v})$ by means of a Teflon cannula inserted $8 \mathrm{~cm}$ through the anus. Rats from the non-colitic group were administered intracolonically $0.25 \mathrm{ml}$ PBS instead of TNBS. All rats were killed with an overdose of halothane 1 week after induction of colitis. After killing, the following tissues were quickly removed and weighed: spleen, thymus, kidneys, liver and soleus muscle. Also the colon was obtained for the assessment of colonic damage.

\section{Assessment of colonic damage}

The body weight, water and food intake, as well as stool consistency, were recorded daily throughout the experiment. Once the rats were killed, the colon was removed aseptically and placed on an ice-cold plate, longitudinally opened and the luminal contents were collected for the measurements of faecal moisture, $\mathrm{pH}$ and microbiological and SCFA production studies (see later). Afterwards, the colonic segment was cleaned of fat and mesentery, blotted on filter paper; each specimen was weighed and its length measured under a constant load $(2 \mathrm{~g})$. The colon was scored for macroscopically visible damage on a $0-10$ scale by two observers unaware of the treatment, according to the criteria described by Bell et al. (1995), which takes into account the extent as well as the severity of colonic damage. Representative whole gut specimens were taken from a region of the inflamed colon corresponding to the adjacent segment to the gross macroscopic damage and were fixed in $4 \%$ buffered formaldehyde. Cross-sections were selected and embedded in paraffin. Equivalent colonic segments were also obtained from the non-colitic group. Full-thickness sections of $5 \mu \mathrm{m}$ were taken at different levels and stained with haematoxylin and eosin. The histological damage was evaluated on a $0-27$ scale by two pathologist observers (A. N. and A. C.), who were blinded to the experimental groups, according to the criteria described previously (Camuesco et al. 2005). The colon was subsequently divided into four segments for biochemical determinations. Two 
fragments were frozen at $-80^{\circ} \mathrm{C}$ for myeloperoxidase (MPO) activity and iNOS and cyclo-oxygenase-2 (COX-2) expressions, and another sample was weighed and frozen in $1 \mathrm{ml}$ TCA $(50 \mathrm{~g} / \mathrm{l})$ for total glutathione content determinations. The remaining sample was immediately processed for the measurement of colonic TNF $\alpha$, IL-1 $\beta$, IL-10 and leukotriene B4 $\left(\mathrm{LTB}_{4}\right)$ levels. All biochemical measurements were completed within 1 week from the time of sample collection and were performed in duplicate.

MPO activity was measured according to the technique described by Krawisz et al. (1984). The results are expressed as MPO units per $\mathrm{g}$ wet tissue; one unit MPO activity was defined as that degrading $1 \mu \mathrm{mol} \mathrm{H}_{2} \mathrm{O}_{2} / \mathrm{min}$ at $25^{\circ} \mathrm{C}$. Glutathione (reduced and oxidised) concentrations were assayed by HPLC with fluorimetric detection of oxidised and reduced glutathione, according to the method proposed by Martin \&White (1991); the results are expressed as nmol glutathione/mg wet tissue. Colonic samples for cytokine and $\mathrm{LTB}_{4}$ determinations were immediately weighed, minced on an ice-cold plate and suspended in a tube with $10 \mathrm{~mm}-$ sodium phosphate buffer $(\mathrm{pH} 7 \cdot 4)(1: 5, \mathrm{w} / \mathrm{v})$. The tubes were placed in a shaking water-bath $\left(37^{\circ} \mathrm{C}\right)$ for $20 \mathrm{~min}$ and centrifuged at $9000 \mathrm{~g}$ for $30 \mathrm{~s}$ at $4^{\circ} \mathrm{C}$; the supernatant fractions were frozen at $-80^{\circ} \mathrm{C}$ until assay. TNF $\alpha$, IL-1 $\beta$ and IL-10 were quantified by ELISA (Amersham Pharmacia Biotech, Amersham, Bucks, UK) and the results were expressed as $\mathrm{pg} / \mathrm{mg}$ protein; the detection limits were $31-2500 \mathrm{pg} / \mathrm{ml}$ for $\mathrm{TNF} \alpha, 25 \cdot 6-2500 \mathrm{pg} / \mathrm{ml}$ for IL-1 $\beta$ and $16-500 \mathrm{pg} / \mathrm{ml}$ for IL-10. $\mathrm{LTB}_{4}$ was determined by enzyme immunoassay (Amersham Pharmacia Biotech) and the results expressed as pg/mg protein; the detection limits were $6 \cdot 2-800 \mathrm{pg} / \mathrm{ml}$.

The colonic expression of iNOS and COX-2 was analysed by Western blotting as previously described (Camuesco et al. 2004). The dilutions of each primary antibody were 1:2000 for iNOS (Transduction Laboratories, Becton Dickinson Biosciences, Madrid, Spain) and 1:1000 for COX-2 (Cayman Chemical Company, Montigny le Bretonneux, France), and incubated overnight at $4^{\circ} \mathrm{C}$ followed by peroxidase-conjugated anti-rabbit IgG antibody (1:3000) for $1 \mathrm{~h}$. Control of protein loading and transfer was conducted by detection of the $\beta$-actin levels.

\section{pH, moisture and short-chain fatty acid quantification in colonic contents}

The $\mathrm{pH}$ values in the colonic contents were measured using a GLP21-21 pH-meter (Crison, Barcelona, Spain) after their suspension in water $(1: 5, \mathrm{w} / \mathrm{v})$. The water content of the luminal stools was calculated by weight differences between fresh (immediately after collection) and dried (kept during $24 \mathrm{~h}$ at $65^{\circ} \mathrm{C}$ ) samples.

To quantify the SCFA concentrations in the colonic luminal contents, the samples were homogenised with $150 \mathrm{~mm}$ $\mathrm{NaHCO}_{3}(\mathrm{pH} 7.8)(1: 5, \mathrm{w} / \mathrm{v})$ in an $\mathrm{Ar}$ atmosphere. Samples were incubated for $24 \mathrm{~h}$ at $37^{\circ} \mathrm{C}$ and stored at $-80^{\circ} \mathrm{C}$ until the extraction. To extract the SCFA, $50 \mu \mathrm{l}$ of the internal standard 2-methylvaleric acid (100 mM), $10 \mu \mathrm{l}$ sulfuric acid and $0.3 \mathrm{ml}$ ethyl acetate were added to $1 \mathrm{ml}$ of the homogenate and, then, centrifuged at $10000 \mathrm{~g}$ for $5 \mathrm{~min}$ at $4{ }^{\circ} \mathrm{C}$. The supernatant fractions were dehydrated with sodium sulfate anhydrous and centrifuged at $10000 \mathrm{~g}$ for $5 \mathrm{~min}$ at $4^{\circ} \mathrm{C}$. Later,
$0.5 \mathrm{ml}$ of the sample was splitless inoculated into a gas chromatograph (Varian CP-3800) equipped with an ID (CPWAX $52 \mathrm{CB} 60 \mathrm{~m} \times 0.25 \mathrm{~mm})$, and connected to a FID detector (Varian, Lake Forest, CA, USA). The carrier and the makeup gas was $\mathrm{He}$, with a flow rate of $1.5 \mathrm{ml} / \mathrm{min}$. The injection temperature was $250^{\circ} \mathrm{C}$. Acetate, propionate and butyrate concentrations were automatically calculated from the areas of peaks using the Star Chromatography WorkStation program (version 5.5; Varian Inc., Palo Alto, CA, USA), which was on-line connected to the FID detector.

\section{Microbiological studies}

Luminal content samples were weighed, homogenised and serially diluted in sterile peptone water. Serial 10-fold dilutions of homogenates were plated on specific media for Lactobacillus (MRS media, Oxoid) or Bifidobacterium (MRS media supplemented with dicloxacilin $(0.5 \mathrm{mg} / \mathrm{l}), \mathrm{LiCl}(1 \mathrm{~g} / \mathrm{l})$ and L-cysteine hydrochloride $(0.5 \mathrm{~g} / \mathrm{l}))$ and incubated under anaerobic conditions in an anaerobic chamber for $24-48 \mathrm{~h}$ at $37^{\circ} \mathrm{C}$. Coliforms and enterobacteria were also determined by using specific Count Plates Petrifilm (3M, St Paul, MN, Canada). After incubation, the final count of colonies was reported as $\log _{10}$ colony-forming units per $g$ material.

\section{Statistics}

All results are expressed as means with their standard errors. Differences between means were tested for statistical significance using a one-way ANOVA and post hoc least significance tests. Non-parametric data (scores) are expressed as medians and ranges and were analysed using the Mann-Whitney $U$ test. Differences between proportions were analysed with the $\chi^{2}$ test. All statistical analyses were carried out with the Statgraphics 5.0 software package (STSC, Rockville, MD, USA), with statistical significance set at $P<0 \cdot 05$.

\section{Results}

Effects of probiotic administration on body and tissue weight in colitic rats

The administration of probiotics for 2 weeks before colitis induction did not affect rat weight gain compared with untreated rats (data not shown). The intracolonic administration of TNBS resulted in an intestinal inflammatory status in the rats characterised by anorexia, loss of weight and diarrhoea, which gradually increased. Thus, 1 week after colitis induction, body weight was reduced by 4.5 (SEM 1.9) \% in the TNBS-treated rats, whereas in saline-treated rats it was increased by 4.8 (SEM 0.7$) \%(P<0 \cdot 01)$. Although none of the probiotics were able to inhibit the anorexia and the loss of weight in the acute phase of the inflammation (data not shown), both lactobacilli restored the animals' weight at the end of the study, since it was increased by 0.6 (SEM 2.5) and by 0.88 (SEM 2.6 ) \% in the colitic rats that received L. fermentum or L. reuteri, respectively, without showing statistical differences with control groups.

The anorexia and the inflammatory response caused an important modification in the weight of some tissues such as muscle, thymus, spleen, while liver and kidneys did not 
show any significant changes (Table 1 ). Soleus muscle weight was reduced in colitic rats in comparison with non-colitic rats, although the statistical differences were only obtained in the rats treated with $L$. reuteri. Moreover, the inflammatory process provoked a reduction in thymus weight and an increase in spleen weight. None of the probiotics were able to counteract the increase in spleen weight, and only L. fermentum was able to partially restore the thymus weight.

\section{Effects of probiotic administration on colonic inflammation}

L. fermentum administration showed an amelioration of the diarrhoeic process, resulting in a significantly lower incidence of diarrhoea $(20 \%)$ after $7 \mathrm{~d}$ when compared with untreated control rats $(80 \% ; P<0.05)$ (Table 2). The macroscopic evaluation of the colonic segments 1 week after colitis induction revealed the preventative effect exerted by probiotics. This was evidenced by a significant reduction of the colonic weight:length ratio $(P<0.01)$ in both cases (Table 2$)$, as well as by a significantly lower colonic damage score in comparison with control colitic rats, derived from a decrease in the extent of colonic necrosis and the presence of intestinal adhesions induced by the administration of TNBS (Table 2). However, only the group of colitic rats treated with L. fermentum showed significant reduction in these inflammatory parameters in comparison with untreated colitic control rats; L. reuteri showed only a tendency to decrease them $(P=0.07$; Table 2$)$.

The histological studies revealed that L. fermentum was more efficient in promoting the recovery of colonic tissue than $L$. reuteri. Histological assessment of colonic samples from the TNBS control group showed severe transmural disruption of the normal architecture of the colon, extensive ulceration and inflammation involving all the intestinal layers of the colon, giving a score value of 15.9 (SEM 2.5). The histological analysis of the colonic specimens from rats treated with $L$. fermentum revealed a more pronounced recovery of the intestinal architecture than controls, with a score of 9.4 (SEM 1.9) $(P<0.05 v$. TNBS control group). Thus, most of the samples (eight out of ten) showed almost complete restoration of the epithelial cell layer, in contrast to the extensive ulceration observed in non-treated animals. The improvement in colonic histology was accompanied by a reduction in the inflammatory infiltrate, which was slight to moderate with a patchy distribution, although neutrophils were the predominant cell type. The colonic specimens from colitic rats treated with $L$. reuteri also showed a higher recovery than the intestinal segments from control colitic rats, and they were assigned a score value of 10.8 (SEM 2.5), lower than in the control group, but without showing statistical differences $(P=0 \cdot 14)$. Thus, four out of ten samples showed evident restoration of the epithelial cell layer, while in the rest of the samples the epithelial ulceration of the mucosa affected over $40-50 \%$ of the surface, lower than in most of the specimens from control colitic rats. Similarly, the goblet cell depletion was also attenuated in this group, and the presence of mucin content was evident, together with an absence of dilated crypts. Finally, the inflammatory infiltrate was also attenuated, being moderate with a patchy distribution.

The biochemical analysis of the colonic specimens confirmed the intestinal anti-inflammatory effect exerted by the probiotics, although again some differences were observed in their effects on the different parameters assayed. Colonic MPO activity was reduced after treatment with $L$. reuteri or L. fermentum by approximately $40 \%$ although only L. fermentum treatment reached significance (Table 3 ). Since colonic MPO activity is considered as a biochemical marker of neutrophil infiltration (Krawisz et al. 1984), these results confirm the lower leucocyte infiltration into the inflamed tissue after probiotic treatment observed in the histological studies. Furthermore, treatment of colitic rats with the probiotics showed an increase in colonic glutathione content (Table 3), depleted in colitic rats as a consequence of the colonic oxidative stress caused by the TNBSinduced inflammatory process (Galvez et al. 2003). However, although both probiotics restored the values observed in non-colitic rats, only the group of rats treated with L. fermentum showed statistical differences in comparison with control colitic rats $(P<0 \cdot 01)$. The colonic inflammation induced by TNBS was also characterised by increased levels of colonic TNF $\alpha$ (Table 3), IL-1 $\beta$ (339.5 (SEM 43.9) v. $28.4($ SEM 3.4) $\mathrm{pg} / \mathrm{mg}$ protein in the non-colitic group; $P<0.01$ ) and $\mathrm{LTB}_{4}(146.6$ (SEM 33.1) v. 9.8 (SEM $2.5) \mathrm{pg} / \mathrm{mg}$ protein in the non-colitic group; $P<0.01$ ), and a reduction in IL-10 production $(5 \cdot 1$ (SEM 1.2) $v .18 \cdot 3$ (SEM 3.1) $\mathrm{pg} / \mathrm{mg}$ protein in the non-colitic group; $P<0 \cdot 01)$. Only $\mathrm{TNF} \alpha$ production was significantly reduced after treatment with either $L$. reuteri or $L$. fermentum (Table 3). No statistical differences were observed in the other pro-inflammatory mediators assayed (data not shown).

Finally, the inflammatory process in the colonic tissue was also characterised by higher expression of both iNOS and COX-2 in comparison with non-colitic animals (data not

Table 1. Effects of probiotic treatment on tissue weights in trinitrobenzenesulfonic acid (TNBS) experimental colitis in rats (Mean values with their standard errors for ten rats per group)

\begin{tabular}{|c|c|c|c|c|c|c|c|c|c|c|}
\hline \multirow[b]{2}{*}{ Group } & \multicolumn{2}{|c|}{$\begin{array}{c}\text { Muscle } \\
\text { (mg/g rat) }\end{array}$} & \multicolumn{2}{|c|}{$\begin{array}{c}\text { Liver } \\
\text { (mg/g rat) }\end{array}$} & \multicolumn{2}{|c|}{$\begin{array}{l}\text { Kidneys } \\
\text { (mg/g rat) }\end{array}$} & \multicolumn{2}{|c|}{$\begin{array}{l}\text { Spleen } \\
\text { (mg/g rat) }\end{array}$} & \multicolumn{2}{|c|}{$\begin{array}{l}\text { Thymus } \\
\text { (mg/g rat) }\end{array}$} \\
\hline & Mean & SEM & Mean & SEM & Mean & SEM & Mean & SEM & Mean & SEM \\
\hline Non-colitic & $6 \cdot 6$ & 0.1 & 31.3 & 1.3 & 5.9 & 0.1 & $2 \cdot 2$ & 0.2 & 1.9 & 0.1 \\
\hline TNBS control & $6 \cdot 3$ & 0.2 & 31.9 & $1 \cdot 1$ & $6 \cdot 2$ & 0.1 & $3 \cdot 0^{*}$ & 0.2 & $0.9^{*}$ & 0.1 \\
\hline Lactobacillus reuteri & $6 \cdot 0^{*}$ & 0.1 & $35 \cdot 1$ & 1.3 & 5.9 & 0.2 & $3 \cdot 3^{*}$ & 0.4 & $0.9^{*}$ & 0.1 \\
\hline L. fermentum & $6 \cdot 5 \ddagger$ & 0.1 & 34.9 & $1 \cdot 1$ & $6 \cdot 1$ & 0.2 & $2 \cdot 9^{*}$ & 0.2 & $1 \cdot 2^{*} \dagger \ddagger$ & 0.1 \\
\hline
\end{tabular}

* Mean value was significantly different from that of the non-colitic group $(P<0.05)$.

† Mean value was significantly different from that of the TNBS control group $(P<0.05)$.

$\ddagger$ Mean value was significantly different from that of the $L$. reuteri group $(P<0.05)$. 
Table 2. Effects of probiotic treatment on diarrhoea, adhesions, damage score, extent of the inflammatory lesion along the colon and changes in colon weight in trinitrobenzenesulfonic acid (TNBS) experimental colitis in rats (Percentages, medians and ranges, and mean values with their standard errors for ten rats per group)

\begin{tabular}{|c|c|c|c|c|c|c|c|c|}
\hline \multirow[b]{2}{*}{ Group } & \multirow[b]{2}{*}{ Diarrhoea (\%) } & \multirow[b]{2}{*}{ Adhesions (\%) } & \multicolumn{2}{|c|}{$\begin{array}{c}\text { Damage score } \\
(0-10) \S\end{array}$} & \multicolumn{2}{|c|}{$\begin{array}{c}\text { Extent of } \\
\text { damage }(\mathrm{cm})\end{array}$} & \multicolumn{2}{|c|}{$\begin{array}{l}\text { Weight/length } \\
(\mathrm{mg} / \mathrm{cm})\end{array}$} \\
\hline & & & Median & Range & Mean & SEM & Mean & SEM \\
\hline Non-colitic & 0 & 0 & 0 & 0 & 0 & 0 & 71.0 & 2.5 \\
\hline TNBS control & $80^{*}$ & $80^{*}$ & $7^{*}$ & $6-8.5$ & $3 \cdot 6^{*}$ & 0.3 & $249 \cdot 7^{*}$ & $22 \cdot 1$ \\
\hline Lactobacillus reuteri & $50^{*}$ & $50^{*}$ & $6^{*}$ & $4-8$ & $2 \cdot 8^{*}$ & 0.3 & $175 \cdot 9^{*}$ & 11.9 \\
\hline L. fermentum & $20+$ & $10^{*}+\ddagger$ & $5 \cdot 5^{\star} \ddagger$ & $4-6.5$ & $2 \cdot 4^{*}+$ & 0.3 & $145 \cdot 7^{\star}+\ddagger$ & 7.6 \\
\hline
\end{tabular}

* Percentage or mean value was significantly different from that of the non-colitic group $(P<0.05)$.

†Percentage or mean value was significantly different from that of the TNBS control group $(P<0.05)$.

$\ddagger$ Percentage or mean value was significantly different from that of the $L$. reuteri group $(P<0.05)$.

$\S$ Damage score for each rat was assigned according to the criteria described previously by Bell et al. (1995).

shown). Treatment of colitic rats with L. fermentum resulted in a significant reduction of the expression of both inducible enzymes in eight out of ten rats, whereas $L$. reuteri was only able to significantly reduce iNOS expression, and this was achieved in seven out of ten rats.

Effects of probiotic administration on colonic short-chain fatty acid production and bacterial profile

No clear differences were observed in the $\mathrm{pH}$ values of the colonic contents among the different groups of rats (Table 4). Moreover, although a tendency to increase the faecal water content was observed in all the colitic rats, only those treated with $L$. reuteri showed a significant difference in the faecal moisture (Table 4).

When the colonic contents from colitic control rats were evaluated for SCFA production, no significant reduction in any of their levels was observed compared with non-colitic rats (Table 4). However, a significant reduction in all the analysed SCFA was observed in the L. reuteri-treated group in comparison with all the other experimental groups (colitic or not). In contrast, colitic rats treated with $L$. fermentum showed similar values to those observed in non-colitic rats (Table 4).

Table 3. Effects of probiotic treatment on colonic myeloperoxidase (MPO) activity, glutathione content and tumour necrosis factor $\alpha$ levels in trinitrobenzenesulfonic acid (TNBS) experimental colitis in rats

(Mean values with their standard errors for ten rats per group)

\begin{tabular}{|c|c|c|c|c|c|c|}
\hline \multirow[b]{2}{*}{ Group } & \multicolumn{2}{|c|}{$\begin{array}{l}\text { MPO activity } \\
\text { (units/g)§ }\end{array}$} & \multicolumn{2}{|c|}{$\begin{array}{l}\text { Glutathione } \\
(\mathrm{nmol} / \mathrm{g})\end{array}$} & \multicolumn{2}{|c|}{$\begin{array}{l}\text { TNF } \alpha \\
\text { (pg/mg } \\
\text { protein) }\end{array}$} \\
\hline & Mean & SEM & Mean & SEM & Mean & SE \\
\hline Non-coliti & 80 & 12 & 1479 & 51 & $17 \cdot 8$ & $2 \cdot 2$ \\
\hline TNBS control & $1325^{\star}$ & 144 & $1093^{*}$ & 85 & $74 \cdot 0^{\star}$ & $9 \cdot 6$ \\
\hline $\begin{array}{l}\text { Lactobacillus } \\
\text { reuteri }\end{array}$ & $989^{*}$ & 206 & 1351 & 135 & $42 \cdot 0^{*} \dagger$ & $7 \cdot c$ \\
\hline L. fermentum & 882*†‡ & 114 & $1490 \dagger$ & 112 & $53 \cdot 1^{*} \dagger$ & $11 \cdot 0$ \\
\hline
\end{tabular}

* Mean value was significantly different from that of the non-colitic group $(P<0.05)$. † Mean value was significantly different from that of the TNBS control group $(P<0.05)$.

$\ddagger$ Mean value was significantly different from that of the $L$. reuteri group $(P<0.05)$. $\S$ One unit of MPO activity was defined as that degrading $1 \mu \mathrm{mol} \mathrm{H}_{2} \mathrm{O}_{2} / \mathrm{min}$ at $25^{\circ} \mathrm{C}$.
TNBS colitis also resulted in a significant reduction in colonic lactobacilli and bifidobacteria counts $(P<0 \cdot 05$; Fig. 1$)$, together with an increase in coliforms and enterobacteria $(P<0.05$; data not shown) in comparison with normal rats. Probiotic-treated colitic rats showed higher counts of lactobacilli and bifidobacteria species in the colonic contents than in control colitic rats, without showing statistical differences with the non-colitic control group (Fig. 1 (A)). No statistical differences were observed in the amount of faecal potential pathogenic bacteria such as enterobacteria or coliforms among the three colitic groups (data not shown). As expected, when the lactobacilli:pathogen ratio was evaluated, the inflammatory process did result in a significant decrease in comparison with normal rats; the administration of L. fermentum or L. reuteri resulted in the normalisation of this ratio (Fig. 1 (B)).

\section{Discussion}

The results obtained in the present study are supportive of the helpfulness of the dietary incorporation of probiotics in IBD therapy (Sartor, 2004). Furthermore, they confirm the intestinal anti-inflammatory activity previously shown by this strain of L. fermentum (CECT5716) (Peran et al. 2006) as well as by other strains of L. reuteri (Mao et al. 1996; Madsen et al. 1999; Holma et al. 2001; Moller et al. 2005), although the present study is the first that describes the efficacy of L. reuteri ATCC55730 in the TNBS model of rat colitis.

Both probiotics ameliorated some of the clinical manifestations of this colitis experimental model such as anorexia or diarrhoea and the macroscopic colonic damage; however, L. fermentum treatment seemed to be more effective. In fact, this probiotic significantly attenuated the incidence of diarrhoea and adhesions, increased thymus weight and reduced the colonic weight:length ratio as well as the damage score and extension. On the contrary, L. reuteri treatment did not show significant modifications on most of these parameters; only the colonic weight:length ratio was significantly reduced in comparison with untreated colitic rats.

The reduction in the diarrhoeic process exerted by L. fermentum can be a consequence of an improvement of the gut epithelial cell barrier function, thus contributing to its intestinal anti-inflammatory effect, as has been proposed to occur with other probiotics (Gionchetti et al. 2005). In fact, 
Table 4. Effects of probiotic treatment on faecal $\mathrm{pH}$ and moisture, and on colonic short-chain fatty acid production in trinitrobenzenesulfonic acid (TNBS) experimental colitis in rats

(Mean values and standard deviations for ten rats per group)

\begin{tabular}{|c|c|c|c|c|c|c|c|c|c|c|c|c|}
\hline \multirow[b]{2}{*}{ Group } & \multicolumn{2}{|c|}{ Faecal pH } & \multicolumn{2}{|c|}{$\begin{array}{c}\text { Faecal } \\
\text { moisture }(\%) \S\end{array}$} & \multicolumn{2}{|c|}{$\begin{array}{l}\text { Total SCFA } \\
(\mathrm{mg} / \mathrm{l})\end{array}$} & \multicolumn{2}{|c|}{$\begin{array}{c}\text { Acetate } \\
(\mathrm{mg} / \mathrm{l})\end{array}$} & \multicolumn{2}{|c|}{$\begin{array}{l}\text { Propionate } \\
\text { (mg/l) }\end{array}$} & \multicolumn{2}{|c|}{$\begin{array}{l}\text { Butyrate } \\
\text { (mg/l) }\end{array}$} \\
\hline & Mean & SD & Mean & SD & Mean & SD & Mean & SD & Mean & SD & Mean & SD \\
\hline Non-colitic & 7.05 & 0.06 & 68.9 & 3.5 & 10388 & 3655 & 6922 & 2917 & 2335 & 708 & 1130 & 267 \\
\hline TNBS control & $7 \cdot 26$ & 0.04 & $72 \cdot 2$ & 1.4 & 7662 & 1290 & 4978 & 847 & 1858 & 322 & 825 & 177 \\
\hline Lactobacillus reuteri & $7 \cdot 32$ & 0.06 & $78 \cdot 5^{*}$ & $1 \cdot 1$ & $2821^{*} \dagger$ & 75 & $1822^{*} \dagger$ & 44 & $556^{*} \dagger$ & 40 & $299^{*} \dagger$ & 20 \\
\hline L. fermentum & $7 \cdot 31$ & 0.03 & $76 \cdot 1$ & $1 \cdot 1$ & $9659 \ddagger$ & 2298 & $6830 \ddagger$ & 1888 & $2896 \ddagger$ & 908 & $1028 \ddagger$ & 279 \\
\hline
\end{tabular}

* Mean value was significantly different from that of the non-colitic group $(P<0.05)$

† Mean value was significantly different from that of the TNBS control group $(P<0.05)$.

$\ddagger$ Mean value was significantly different from that of the $L$. reuteri group $(P<0.05)$.

$\S$ Faecal moisture was expressed as the proportion in water content expressed in \%.

microscopic evaluation showed that the restoration in the epithelial lining was more evident in the rats administered L. fermentum ( $80 \%$ of the samples showed complete restoration) than in those that received $L$. reuteri $(40 \%)$. This may be interesting since a barrier disruption leads to increased stimulation by luminal antigens. In this regard, mucosal inflammation can be considered a self-perpetuating process in which the disruption of the epithelial layer plays a central role (Heyman et al. 1994).

L. fermentum and L. reuteri were able to reduce neutrophil infiltration in the inflamed colon, as was observed in the
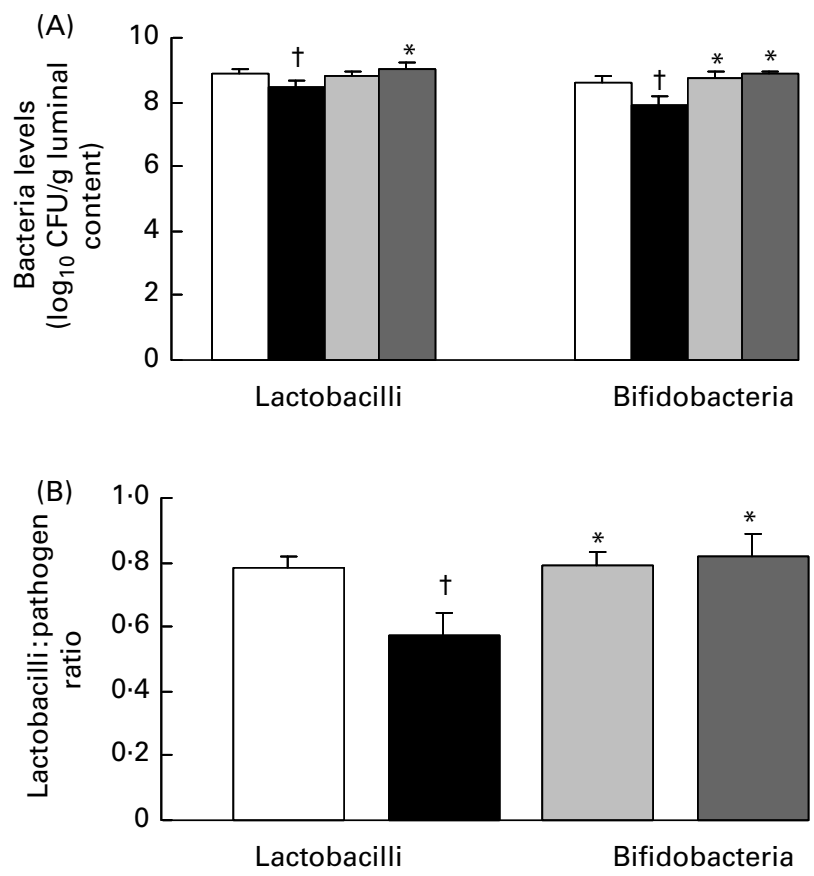

Fig. 1. Effects of probiotic treatment $\left(5 \times 10^{8}\right.$ colony-forming units (CFU)/rat.per d) on (A) bacteria levels (lactobacilli and bifidobacteria) and on (B) lactobacilli:pathogen ratio in trinitrobenzenesulfonic acid (TNBS) experimental colitis in rats. ( $\square$ ), Non-colitic group; ( $\square$ ),TNBS control group; $(\square)$, Lactobacillus reuteri-treated group; $(\square)$, L. fermentum-treated group. Values are means, with their standard errors represented by vertical bars. *Mean value was significantly different from that of the TNBS control group $(P<0.05)$. †Mean value was significantly different from that of the non-colitic group $(P<0.01)$. microscopic analysis, although only L. fermentum treatment significantly decreased colonic MPO activity. The inhibition of neutrophil infiltration can account for their intestinal antiinflammatory effect, given the important role attributed to these cells in the inflammatory process.

L. fermentum treatment of TNBS colitic rats counteracted the depletion of colonic glutathione levels that took place in control colitic animals. This activity may play a crucial role in the intestinal anti-inflammatory effect of the probiotic because a situation of intense oxidative insult is an important mechanism for tissue damage during chronic intestinal inflammation and thus a common feature in human IBD (Grisham, 1994) as well as in the different experimental models of rat colitis, including the TNBS (Galvez et al. 2003) and the dextran sodium sulfate (Camuesco et al. 2004) models. The effect exerted by this probiotic could be due to its ability to release glutathione and the antioxidant dipeptide $\gamma$-Glu-Cys (Peran et al. 2006).

When other pro-inflammatory mediators were evaluated, L. fermentum and $L$. reuteri were able to significantly reduce colonic TNF $\alpha$ production. This may be relevant since this cytokine plays a key role in intestinal inflammation, and different drugs capable of interfering with the activity of this mediator are being developed for IBD therapy (Rutgeerts et al. 2004). Previous in vitro studies have also shown the ability of different probiotic, including L. casei, L. bulgaricus, L. fermentum or L. salivarius ssp. salivarius, to down regulate TNF $\alpha$ production (Borruel et al. 2002; Peran et al. 2005, 2006).

A common feature of both probiotics assayed is their ability to modify colonic microflora, which was altered as a consequence of the TNBS-induced inflammatory process (Peran et al. 2006). In this regard, the probiotic treatment restored the pathogenic bacteria:lactobacilli ratio. This effect could definitively contribute to the beneficial effect exerted by these probiotics in the TNBS model of experimental colitis. In fact, it has been previously described that the increase in Lactobacillus sp. levels reduces the concentration of adherent and translocated bacteria and attenuates the colitis in IL-10 gene-deficient mice (Madsen et al. 1999). This could prevent the pathogenic effect of other species that may contribute to the generation of an exacerbated immune response in intestinal inflammation, as proposed both in experimental models (Garcia-Lafuente et al. 1997) and in human subjects (Cummings et al. 2003). 
However, the colonic SCFA content profiles shown by the two probiotics were different. Thus, L. fermentum was able to significantly counteract the decrease in colonic SCFA production observed in TNBS colitic rats, whereas $L$. reuteri treatment reduced even more the SCFA production despite its effect on colonic microbiota. The effect of $L$. fermentum on butyrate production is very interesting since it has been proposed that the inflammatory process results in an alteration of the intestinal epithelial cell function, including colonic SCFA utilisation, mainly butyrate, which is considered the most important SCFA for colonocyte metabolism (Mortensen \& Clausen, 1996; Rodriguez-Cabezas et al. 2002).

In conclusion, L. fermentum and $L$. reuteri have shown intestinal anti-inflammatory activity in the TNBS model of rat colitis. However, each probiotic shows its own anti-inflammatory profile, confirming that not all probiotics present the same efficacy as anti-inflammatory agents, and do not share the same mechanisms of action. Of note, L. fermentum can be considered more effective than $L$. reuteri, a probiotic with reputed efficacy in promoting beneficial effects on human health (Valeur et al. 2004). Both probiotics can be found in breast milk, and although the doses administered to rats in the present study are higher than those probably incorporated in the infant by breast milk, the present results suggest that the colonisation of these probiotics in the colonic lumen would result in beneficial preventative effects in these intestinal conditions, probably derived from their immunomodulatory properties. Human clinical studies will be required in order to confirm these results.

\section{Acknowledgements}

The present study was supported by the Spanish Ministry of Science and Technology (SAF2005-03 199) and by Instituto de Salud 'Carlos III' (PI021732), with funds from the European Union, and by Junta de Andalucia (CTS 164). M. C. is a recipient of Juan de la Cierva Programme from Spanish Ministry of Science and Technology; L. P. is a recipient from Puleva Foundation (Spain); E. B. is a recipient from the Spanish Ministry of Education and Science.

\section{References}

Bell CJ, Gall DG \& Wallace JL (1995) Disruption of colonic electrolyte transport in experimental colitis. Am J Physiol 268, G622-G630.

BioGaia (2006) http://www.biogaia.se/?id=2622.

Boris S, Jimenez-Diaz R, Caso JL \& Barbes C (2001) Partial characterization of a bacteriocin produced by Lactobacillus delbrueckii subsp. lactis UO004, an intestinal isolate with probiotic potential. J Appl Microbiol 91, 328-333.

Borruel N, Carol M, Casellas F, Antolin M, de Lara F, Espin E, Naval J, Guarner F \& Malagelada JR (2002) Increased mucosal tumour necrosis factor alpha production in Crohn's disease can be downregulated ex vivo by probiotic bacteria. Gut 51, 659-664.

Camuesco D, Comalada M, Rodriguez-Cabezas ME, Nieto A, Lorente MD, Concha A, Zarzuelo A \& Galvez J (2004) The intestinal anti-inflammatory effect of quercitrin is associated with an inhibition in iNOS expression. Br J Pharmacol 143, 908-918.

Camuesco D, Peran L, Comalada M, Nieto A, Di Stasi LC, Rodriguez-Cabezas ME, Concha A, Zarzuelo A \& Galvez J (2005)
Preventative effects of lactulose in the trinitrobenzenesulphonic acid model of rat colitis. Inflamm Bowel Dis 11, 265-271.

Chen CC, Louie S, Shi HN \& Walker WA (2005) Preinoculation with the probiotic Lactobacillus acidophilus early in life effectively inhibits murine Citrobacter rodentium colitis. Pediatr Res 58, $1185-1191$.

Christensen HR, Frokiaer H \& Pestka JJ (2002) Lactobacilli differentially modulate expression of cytokines and maturation surface markers in murine dendritic cells. J Immunol 168, 171-178.

Collado MC, Hernandez M \& Sanz Y (2005) Production of bacteriocin-like inhibitory compounds by human fecal Bifidobacterium strains. J Food Prot 68, 1034-1040.

Cummings JH, MacFarlane GT \& MacFarlane S (2003) Intestinal bacteria and ulcerative colitis. Curr Issues Intest Microbiol 4, $9-20$.

Galvez J, Garrido M, Rodriguez-Cabezas ME, Ramis I, Sanchez de Medina F, Merlos M \& Zarzuelo A (2003) The intestinal antiinflammatory activity of UR-12746S on reactivated experimental colitis is mediated through downregulation of cytokine production. Inflamm Bowel Dis 9, 363-371.

Garcia-Lafuente A, Antolin M, Guarner F, et al. (1997) Incrimination of anaerobic bacteria in the induction of experimental colitis. Am J Physiol 272, G10-G15.

Gionchetti P, Lammers KM, Rizzello F \& Campieri M (2005) Probiotics and barrier function in colitis. Gut 54, 898-900.

Grisham MB (1994) Oxidants and free radicals in inflammatory bowel disease. Lancet 344, 859-861.

Grisham MB, Olkmer C, Tso P \& Yamada T (1991) Metabolism of trinitrobenzene sulfonic acid by rat colon produces reactive oxygen species. Gastroenterology 101, 540-547.

Heyman M, Darmon N, Dupont C, Dugas B, Hirribaren A, Blaton MA \& Desjeux JF (1994) Mononuclear cells from infants allergic to cow's milk secrete tumor necrosis factor alpha, altering intestinal function. Gastroenterology 106, 1514-1523.

Holma R, Salmenpera P, Lohi J, Vapaatalo H \& Korpela R (2001) Effects of Lactobacillus rhamnosus GG and Lactobacillus reuteri R2LC on acetic acid-induced colitis in rats. Scand J Gastroenterol 36, 630-635.

Jurjus AR, Khoury NN \& Reimund JM (2004) Animal models of inflammatory bowel disease. J Pharmacol Toxicol Methods 50, 81-92.

Klement E, Cohen RV, Boxman J, Joseph A \& Reif S (2004) Breastfeeding and risk of inflammatory bowel disease: a systematic review with meta-analysis. Am J Clin Nutr 80, 1342-1352.

Krawisz JE, Sharon P \& Stenson WF (1984) Quantitative assay for acute intestinal inflammation based on myeloperoxidase activity. Assessment of inflammation in rat and hamster models. Gastroenterology 87, 1344-1350.

Kunz C, Rudloff S, Baier W, Klein N \& Strobel S (2000) Oligosaccharides in human milk: structural, functional, and metabolic aspects. Аппи Rev Nutr 20, 699-722.

Ma D, Forsythe P \& Bienenstock J (2004) Live Lactobacillus reuteri is essential for the inhibitory effect on tumor necrosis factor alphainduced interleukin-8 expression. Infect Immun 72, 5308-5314.

Mack DR, Michail S, Wei S, McDougall L \& Hollingsworth MA (1999) Probiotics inhibit enteropathogenic E. coli adherence in vitro by inducing intestinal mucin gene expression. Am J Physiol 276, G941-G950.

Madsen K, Cornish A, Soper P, McKaigney C, Jijon H, Yachimec C, Doyle J, Jewell L \& De Simone C (2001) Probiotic bacteria enhance murine and human intestinal epithelial barrier function. Gastroenterology 121, 580-591.

Madsen K, Doyle J, Jewell L, Tavernini M \& Fedorak R (1999) Lactobacillus species prevents colitis in interleukin 10 genedeficient mice. Gastroenterology 116, 1107-1114.

Mao Y, Nobaek S, Kasravi B, Adawi D, Stenram U, Molin G \& Jeppsson B (1996) The effects of Lactobacillus strains and oat 
fiber on methotrexate-induced enterocolitis in rats. Gastroenterology 111, 334-344.

Martin J \& White INH (1991) Fluorimetric determination of oxidized and reduced glutathione in cells and tissues by high performance liquid chromatography following derivatization with dansyl chloride. J Chromatogr 568B, 219-225.

Martin R, Langa S, Reviriego C, Jiminez E, Marin ML, Xaus J, Fernandez L \& Rodriguez JM (2003) Human milk is a source of lactic acid bacteria for the infant gut. J Pediatr 143, 754-758.

Martin R, Olivares M, Marin ML, Fernandez L, Xaus J \& Rodriguez JM (2005) Probiotic potential of 3 Lactobacilli strains isolated from breast milk. J Hum Lact 21, 8-17.

Moller PL, Paerregaard A, Gad M, Kristensen NN \& Claesson MH (2005) Colitic scid mice fed Lactobacillus spp. show an ameliorated gut histopathology and an altered cytokine profile by local T cells. Inflamm Bowel Dis 11, 814-819.

Morris GP, Beck PL, Herridge W, Depew W, Szewczuk MR \& Wallace JL (1989) Hapten induced model of chronic inflammation and ulceration in rat colon. Gastroenterology 96, 795-803.

Mortensen PB \& Clausen MR (1996) Short-chain fatty acids in the human colon: relation to gastrointestinal health and disease. Scan J Gastroenterol 31, 132S-148S.

Pathmakanthan S, Li CK, Cowie J \& Hawkey CJ (2004) Lactobacillus plantarum 299: beneficial in vitro immunomodulation in cells extracted from inflamed human colon. $J$ Gastroenterol Hepatol 19, 166-173.

Peran L, Camuesco D, Comalada M, Nieto A, Concha A, Adrio JL, Olivares M, Xaus J, Zarzuelo A \& Galvez J (2006) Lactobacillus fermentum, a probiotic capable to release glutathione, prevents colonic inflammation in the TNBS model of rat colitis. Int $J$ Colorectal Dis 21, 737-746.

Peran L, Camuesco D, Comalada M, Nieto A, Concha A, DiazRopero MP, Olivares M, Xaus J, Zarzuelo A \& Galvez J (2005) Preventative effects of a probiotic, Lactobacillus salivarius ssp. salivarius, in the TNBS model of rat colitis. World J Gastroenterol 11, 5185-5192.

Rembacken BJ, Snelling AM, Hawkey PM, Chalmers DM \& Axon AT (1999) Non-pathogenic Escherichia coli versus mesalazine for the treatment of ulcerative colitis: a randomised trial. Lancet 354, 635-639.

Rodriguez-Cabezas ME, Galvez J, Lorente MD, Concha A, Camuesco D, Azzouz S, Osuna A, Redondo L \& Zarzuelo A (2002) Dietary fiber down-regulates colonic tumor necrosis factor alpha and nitric oxide production in trinitrobenzenesulfonic acidinduced colitic rats. $J$ Nutr 132, 3263-3271.

Rutgeerts P, Van Assche G \& Vermeire S (2004) Optimizing antiTNF treatment in inflammatory bowel disease. Gastroenterology 126, $1593-1610$

Sakata T, Kojima T, Fujieda M, Takahashi M \& Michibata T (2003) Influences of probiotic bacteria on organic acid production by pig caecal bacteria in vitro. Proc Nutr Soc 62, $73-80$.

Sartor RB (2004) Therapeutic manipulation of the enteric microflora in inflammatory bowel diseases: antibiotics, probiotics, and prebiotics. Gastroenterology 126, 1620-1633.

Schultz M, Linde HJ, Lehn N, Zimmermann K, Grossmann J, Falk W \& Scholmerich J (2003) Immunomodulatory consequences of oral administration of Lactobacillus rhamnosus strain GG in healthy volunteers. J Dairy Res 70, 165-173.

Valeur N, Engel P, Carbajal N, Connolly E \& Ladefoged K (2004) Colonization and immunomodulation by Lactobacillus reuteri ATCC 55730 in the human gastrointestinal tract. Appl Environ Microbiol 70, 1176-1181.

Venturi A, Gionchetti P, Rizzello F, Johansson R, Zucconi E, Brigidi P, Matteuzzi D \& Campieri M (1999) Impact on the composition of the faecal flora by a new probiotic preparation: preliminary data on maintenance treatment of patients with ulcerative colitis. Aliment Pharmacol Ther 13, 1103-1108. 